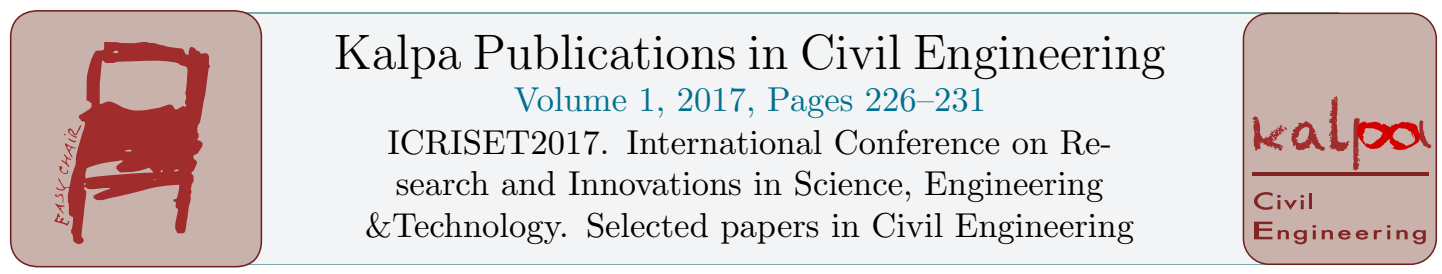

\title{
Seismic Vibration Control of Building with Lead Rubber Bearing Isolator
}

\author{
Kishan Bhojani ${ }^{1}$, Vishal B. Patel ${ }^{2}$ and Snehal V. Mevada ${ }^{3}$ \\ ${ }^{1}$ Research Scholar, Structural Engineering Department, BVM-VVNagar, Anand \\ ${ }^{2}$ Assistant Professor, Structural Engineering Department, BVM-VVNagar, Anand \\ ${ }^{3}$ Assistant Professor, Structural Engineering Department, BVM-VVNagar, Anand
}

\begin{abstract}
During the life span of structure there may be an effect of vibration. Due to vibration there may be major or minor damage in building. Base isolation is best method to reduce the seismic response of the structure. This paper gives idea about base isolation system which can be used in multi-story building to reduce seismic response of the structure. This paper represents the initialize study of dynamic parameter like effective damping for four earthquake time history. In this paper the optimum effective damping has been found out under the effect of Loma Prieta earthquake time history. The parametric study has been conducted to evaluate the effect on maximum displacement, maximum acceleration, maximum base shear in bare frame and frame with isolator.
\end{abstract}

\section{Introduction}

The traditional technique of a seismic design is to increase the stiffness of structures by increase the size of beams, columns and shear walls and hence the consumption of material are increased and open space area reduced. To overcome these, there are some Modern technique through structural controls by which we can reduce structural vibrations during strong winds and Earthquakes. The structural control system can be classified into active control system, passive control system, semiactive control system and hybrid control system.

Base isolation is one type of passive control system which are being widely used in any structural system to minimize structural damage cause by lateral load by enlarge. Normally, a building is supported directly on its foundation, and it is said to have a fixed-base or restrained. When base isolation is used, special structural bearing are inserted between superstructure and substructure. These bearings are not very stiff in the horizontal direction, so that they reduce the fundamental frequency of vibration of any structure. This is generally suitable for short to medium height structures.

In the past, researchers have studied dynamic analysis of structures with or without base isolation system. Sabu et al. [1] investigated fix-base and isolated base building and linear static and nonlinear 
dynamic analysis are carried out for three different types of soil type. From analysis it was concluded that for medium rise building, base-isolation reduce seismic response of the building and in harder soil the reduction is even more. A fourteen story building analyzed with three different seismic protection, fixed base friction pendulum bearing and rubber bearing by Shirule et al. [2]. From the analysis it was observed that reduction in the forces indicates that the performance of the base isolation is extremely good in earthquake prone area. A nonlinear time history analysis is carried out for reinforced concrete building by use of computer tool SAP 2000 by Anilduke and Khedikar [3]. In the study Rubber bearing and Friction pendulum bearing are used as passive energy dissipation device. The analysis results shows that the percentage reduction in base shear for RB and FPB is respectively $85 \%$ and 95\%. Zohaï and Abdelhafid [4] investigated 8 story building installed with rubber bearing. Effective damping of bearing varies from $8 \%$ to $35 \%$ it is concluded that there is a significant reduction in base shear, displacement and acceleration. Warrier et al. [5] analysed the building in which laminated rubber bearing are used as base isolator. It is concluded that thickness of the isolator decreases with increase in damping. In linear analysis the displacement is increased while in non-linear analysis displacement is decreased.

\section{Objective of Work}

The current literature survey suggest that there is a research gap of utilization of hybrid system. The author aim to study the behavior of structural system under the simultaneous effect of isolator and damper (hybrid). The objective of work is to compare the maximum displacement, maximum acceleration and maximum base shear in bare frame and bare frame with isolator for optimum damping.

\section{Numerical Study}

In the present work for comparing a fixed base and isolated base building a $\mathrm{G}+2$ story regular plan building is modeled in the ETABS software and time history analysis is carried out under Loma Prieta earthquake.

\section{A. Building Data}

- Floor height $: 5 \mathrm{~m}$

- Column size $: 0.45 \mathrm{~m} \mathrm{X} 0.45 \mathrm{~m}$

- Beam size $\quad: 0.30 \mathrm{~m} \times 0.30 \mathrm{~m}$

- Slab thickness : $0.150 \mathrm{~m}$

- Grade of steel : Fe-415

- Concrete Grade: M20

\section{B. Loading Data}

- Dead load:

- Self-weight of slab: $3.75 \mathrm{kN} / \mathrm{m}^{2}$

- $\quad$ Floor finish $=1 \mathrm{kN} / \mathrm{m}^{2}$

- Terrace water proofing $=1.5 \mathrm{kN} / \mathrm{m}^{2}$

- Live load

- Typical Floor $=3.5 \mathrm{kN} / \mathrm{m}^{2}$

- $\quad$ Roof $=1.5 \mathrm{kN} / \mathrm{m}^{2}$ 


\section{Modelling of Building}

For this building maximum displacement and maximum acceleration values are obtained from ETABS (software). In the present study, a simple bare frame and frame with base isolation has been taken. Here isolator is provided at the base of the building. The base floor is not modelled in the building and it is assumed that the columns rest directly on isolators.

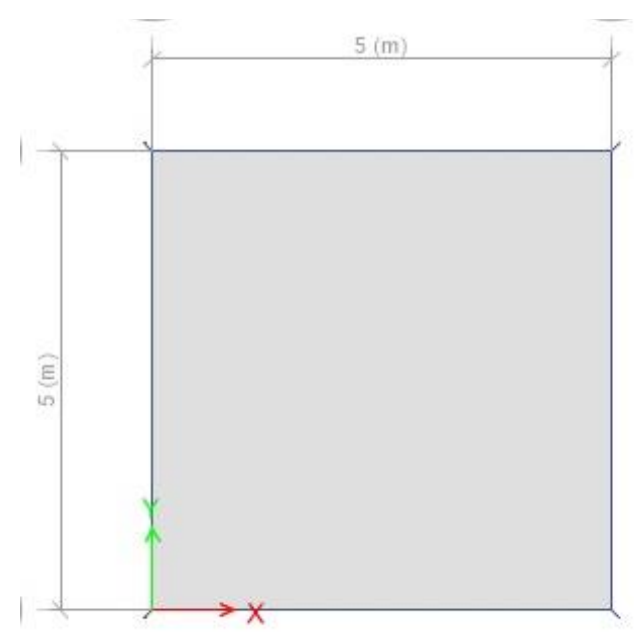

Figure 1: Plan of Building

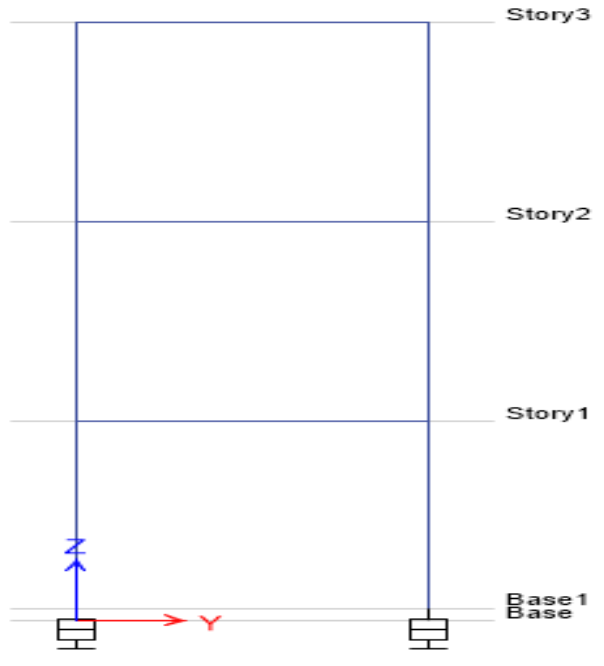

Figure 2: Elevation of Building

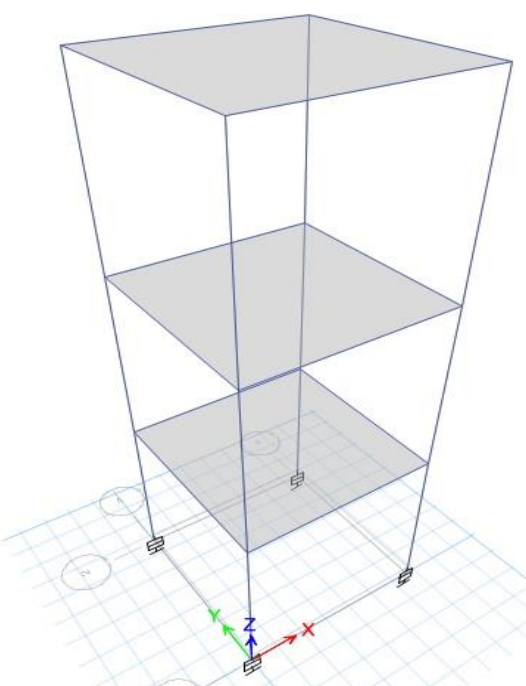

Figure 3: 3D View of Building 


\section{Earthquake Time history}

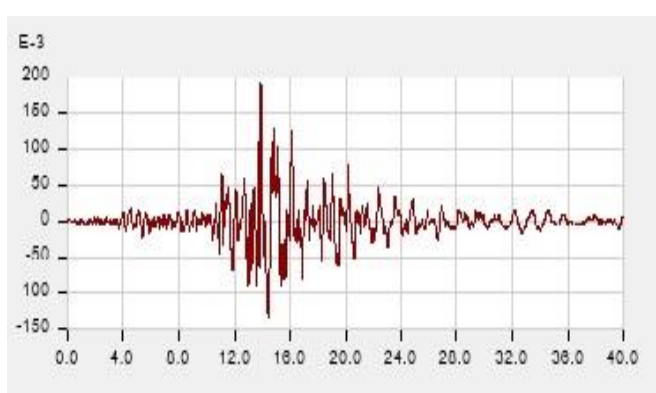

Fig. 4(a) Time history of Loma Prieta earthquake in X-direction

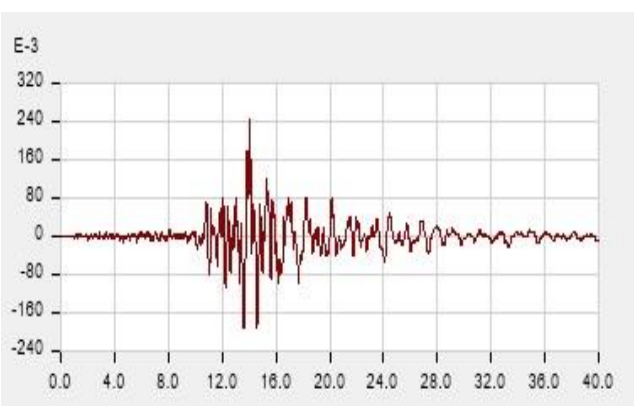

Fig. 4(b) Time history of Loma Prieta earthquake in Y-direction

Figure 4: Time history of Loma Prieta earthquake in X \& Y directions.

\section{Results and Discussion}

For the different values of damping corresponding displacement and acceleration values are calculated as shown in figure $5 \& 6$. It is observed from the figures $5 \& 6$ that with the increase in damping, the displacement and acceleration of building reduces. It is further observed that the rate of decrease of response is significant up to the damping of $1300 \mathrm{kN}-\mathrm{s} / \mathrm{m}$ and then the effect remains constant. Hence, for the present numerical study the optimum value of damping is considered as 1300 $\mathrm{kN}-\mathrm{s} / \mathrm{m}$ such as to obtain maximum reduction in response. Following isolator property has been considered.

A. Properties of LRB Isolator for Base Isolation

- Linear Effective Stiffness in vertical direction: $1500000 \mathrm{kN} / \mathrm{m}$

- $\quad$ Linear Effective Stiffness in horizontal direction: 800 kN/m

- $\quad$ Linear Effective Damping in horizontal direction: $1300 \mathrm{kN}-\mathrm{s} / \mathrm{m}$

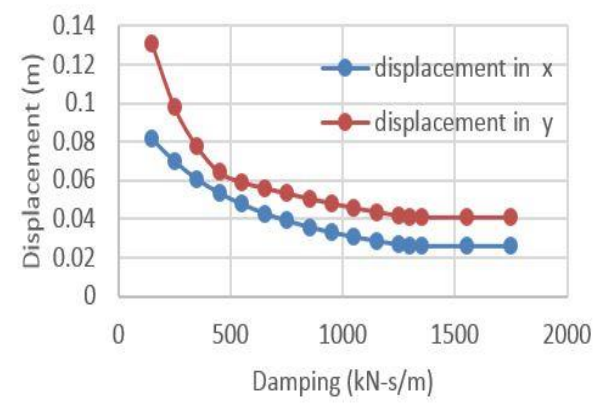

Figure 5: Displacement v/s damping

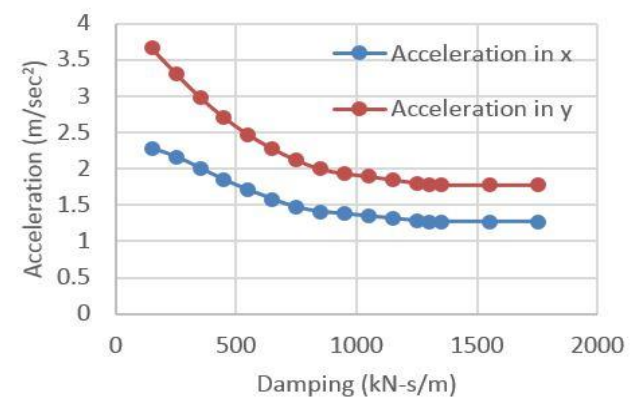

Figure 6: Acceleration v/s damping

Here Analysis is carried out by imposing time history on fixed base and isolated base structure for $\mathrm{X}$ and $\mathrm{Y}$ direction. Figures $7 \& 8$ represents the variation of displacement of fixed base building and 
building with isolator. While figure $9 \& 10$ represents the variation of acceleration of fixed base building and building with isolator. It is observed from figures, that the displacement and acceleration in both direction of building reduces significant with the isolator at the base. This reflects the effectiveness of isolator in reducing the superstructure response. Maximum Base shear for $\mathrm{x}$ and $\mathrm{y}$ direction are shown in figure 11.

Natural time period for fixed base building is 0.901 seconds and for isolated building it is 1.641 seconds. The time period of isolated building essentially depends on the properties of isolators. To increase the time period and hence to improve the effectiveness of isolators, the response can also be obtained by varying isolator stiffness and optimum damping.

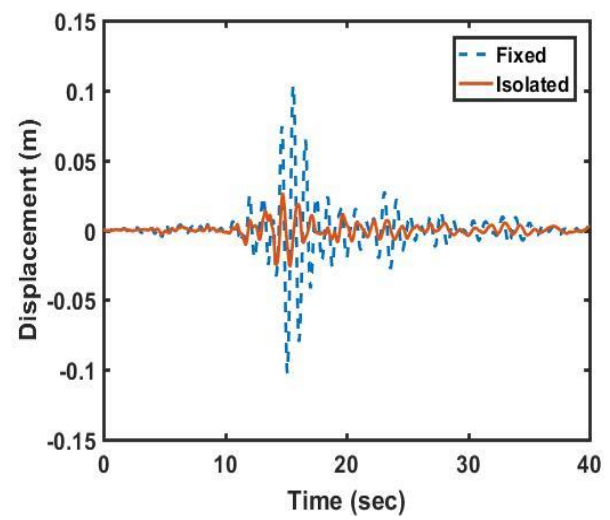

Figure 7: Variation of displacement against time under Loma Prieta earthquake in $\mathrm{X}$-direction

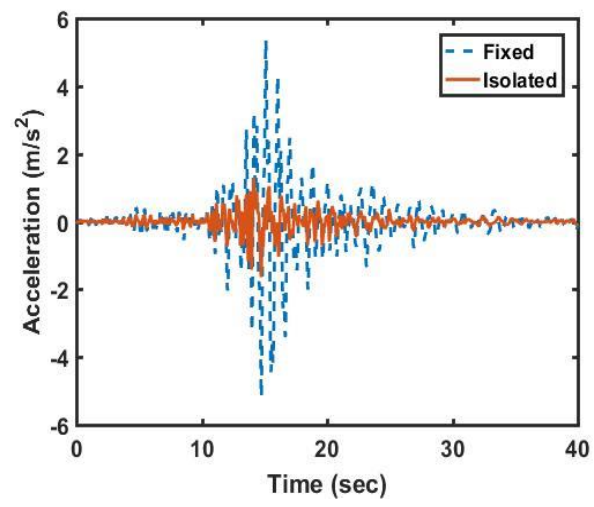

Figure 9: Variation of acceleration against time under Loma Prieta earthquake in Xdirection

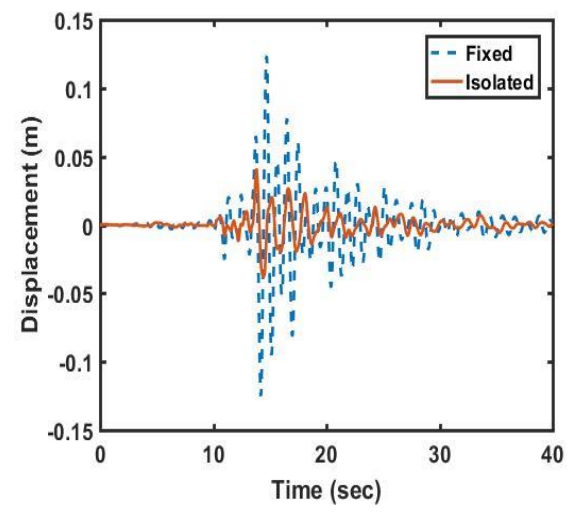

Figure 8: Variation of displacement against time under Loma Prieta earthquake in Y-direction

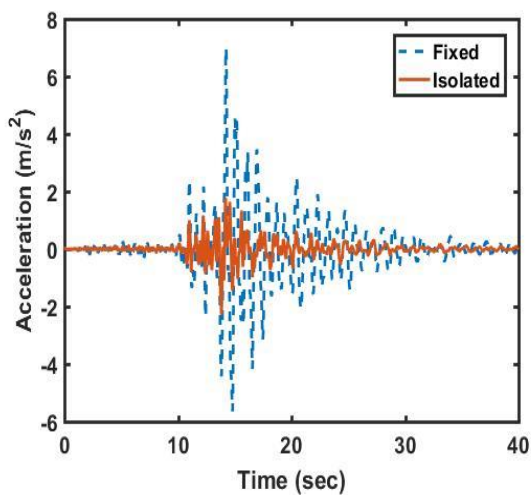

Figure 10: Variation of acceleration against time under Loma Prieta earthquake in Y-direction 


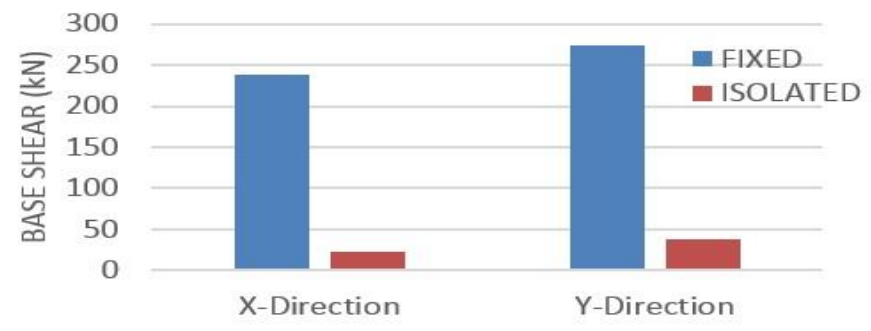

Figure 11: Maximum Base Shear

From the figure 11 it can be concluded that for isolated building base shear value is much lower than fixed base.

The analysis results shows that by installing base isolator in building the percentage reduction in base shear in $\mathrm{x}$-direction and y-direction is $90 \%$ and $86 \%$ respectively. The percentage reduction in displacement in $\mathrm{x}$-direction and $\mathrm{y}$-direction is $75 \%$ and $67 \%$ respectively. The percentage reduction in acceleration in $\mathrm{x}$-direction and $\mathrm{y}$-direction is $76 \%$ and $74 \%$ respectively.

\section{Conclusion}

From the results of the present study, the following conclusions are drawn:

1. It is observed that the Lead Rubber Bearing isolator is quite effective in reducing the displacement and acceleration of building.

2. There exists the optimum value of damping of isolator.

3. The isolator is found to be effective in reducing the base shear of building.

\section{References}

S.K. Sabu, H.S.Chore, S.B.Patil "Effectiveness of Lead Rubber Base Isolators, for seismic resistance of Buildings, supported on different soil stratas" International Journal of Electrical, Electronics and Computer Systems, Volume -2, Issue-4, 2014

Shirule Pravin Ashok, Niraj Mehta, Rahulwagh, Mayur Padhiyar, Ankesh Samare And Yogesh Patil "Response spectrum analysis of multi storeyed base-isolated building" International Journal of Civil, Structural, Environmental and Infrastructure Engineering Research and Development, Vol.2, Issue 3, 2012 66-75

Sonali Anilduke, Amay Khedikar "Comparision of building for sesmic response by using base isolation" International Journal of Research in Engineering and Technology, Volume 04, Issue 06, 2015

Kaab Mohamed Zohaï, Ounis Abdelhafid, "Influence of the damping of the seismic base isolation system LRB on the dynamic response of the isolated structures" International Journal Of Civil And Structural Engineering, Volume 1, No 4, 2011

Ganga Warrier A, Balamonica K, Sathish Kumar K, Dhanalakshmi, "Study on laminated rubber bearing base isolators for seismic protection of structures" International Journal of Research in Engineering and Technology Volume 04 Issue: 02, 2015 